\title{
Response of semen parameters to three training modalities
}

\author{
Diana Vaamonde, Ph.D., ${ }^{\mathrm{a}}$ Marzo Edir Da Silva-Grigoletto, Ph.D., ${ }^{\mathrm{b}}$ Juan Manuel García-Manso, \\ Ph.D., ${ }^{\mathrm{c}}$ Ricardo Vaamonde-Lemos, M.D., Ph.D., ${ }^{\mathrm{a}}$ Robert James Swanson, Ph.D., ${ }^{\mathrm{d}}$ and \\ Sergio Carlos Oehninger, M.D., Ph.D. ${ }^{\mathrm{e}}$

\begin{abstract}
${ }^{a}$ Morphological Sciences Department, School of Medicine, University of Córdoba, Córdoba, Spain; ${ }^{\mathrm{b}}$ Andalusian Center of Sports Medicine, Córdoba, Spain; ${ }^{\mathrm{c}}$ Physical Education Department, School of Physical Activity and Sport Sciences, University of Las Palmas de Gran Canaria, Las Palmas de Gran Canaria, Spain; ${ }^{\mathrm{d}}$ Department of Biological Sciences, Old Dominion University and Eastern Virginia Medical School, Norfolk, Virginia; and ${ }^{\mathrm{e}}$ the Jones Institute for Reproductive Medicine, Department of Obstetrics and Gynecology, Eastern Virginia Medical School, Norfolk, Virginia
\end{abstract}

\begin{abstract}
Objective: To investigate the effect of different training modalities on various markers of semen quality.
Design: Crossover study.

Setting: Medical school.

Patient(s): Forty-five men participated voluntarily in the study, being allocated into three groups according to their sports practice.

Intervention(s): None.

Main Outcome Measure(s): Sperm parameters (volume, liquefaction time, $\mathrm{pH}$, viscosity, sperm count, motility, and morphology).

Result(s): Sperm concentration; total sperm number; type "a," "b," and "d" velocity; and morphology were significantly different among the practitioners of the three different training modalities. Morphology was the parameter showing the greatest difference, even reaching clinical relevance for the triathlete group $(4.7 \%$, poor prognosis pattern). In addition, these parameters tended to decrease as training requirements increased.

Conclusion(s): There are differences in the seminal profiles of individuals exercising in different modalities. The differences are more marked as intensity and volume of exercise increase, especially for morphology. These variables ought to be carefully analyzed and taken into account when designing a training protocol, especially with higher-level athletes, so that reproductive function is not compromised. (Fertil Steril ${ }^{\circledR} 2009 ; 92: 1941-6$. (C2009 by American Society for Reproductive Medicine.)
\end{abstract}

Key Words: Male infertility, seminal profile, water polo, triathlon, physically active, training, sports

The last few decades have seen a rising demand for sports activities. Physical exercise is promoted as a panacea for fitness, health, stress reduction, and life quality improvement, a matter of great importance in today's society (1). Despite this increased interest, not having an adequate knowledge of how to perform these activities might, on occasion, lead to the appearance of negative side effects (e.g., lesions, pathologies). For example, a trend toward a decline in reproductive function has been reported not only in women but also in men as expressed by the analysis of the semen (2-5). A number of studies reported on the relevance and effects of physical exercise on reproductive function. This association has been assessed mainly in women because of unequivocal symptoms such as de-

Received June 12, 2008; revised August 13, 2008; accepted September 3, 2008; published online November 14, 2008.

D.V. has nothing to disclose. M.E.D.S.-G. has nothing to disclose. J.M.G.-M. has nothing to disclose. R.V.-L. has nothing to disclose. R.J.S. has nothing to disclose. S.C.O. has nothing to disclose.

Presented in part at the 13th Annual Congress of the European Congress of Sport Sciences, Estoril, Portugal, July 9-12, 2008.

Reprint requests: Diana Vaamonde, Ph.D., Morphological Sciences Department, School of Medicine, Universidad de Córdoba, Avda. Menéndez Pidal s/n 14071, Córdoba, Spain (FAX: 34-957452166; E-mail: fivresearch@yahoo.com). layed menarche, oligomenorrhea, and amenorrhea (6-8) especially in runners $(9,10)$, gymnasts $(11)$, and ballet dancers (12).

Alterations in the reproductive function of male athletes have also been reported $(3,13)$. Early investigations pointed to exercise volume as the variable most affecting reproduction, thus hypothesizing a volume threshold for reproductive disorders (14, 15). Other authors have suggested that exercise intensity is equally deleterious to, or even more so than, volume on reproductive function $(16,17)$. Other parameters inherent in any specific exercise modality can be harmful to the reproductive system, such as bike saddles because of friction (18). We hypothesized that the continued practice of different sports modalities, because of their inherent characteristics (volume and/or training intensity, different energy requirements), can result in differences in the practitioners' seminal profiles. Thus, it was the aim of the present study to analyze the semen profiles of three male populations with different types and levels of physical activity.

\section{MATERIALS AND METHODS Subjects}

The study was approved by the Institutional Review Board of the University of Córdoba, and informed consent was obtained from all participants. Healthy white men volunteered 


\section{FIGURE 1}

Flow diagram of participants. $\mathrm{PA}=$ physically active subjects; WP $=$ water polo players; TA $=$ triathletes .

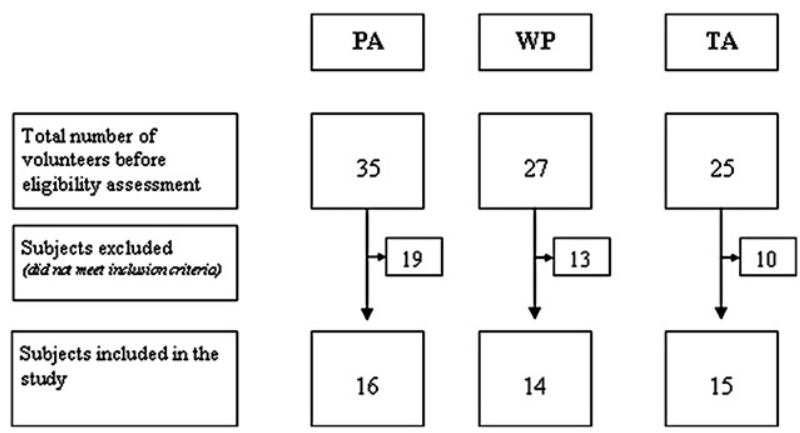

Vaamonde. Semen parameters and exercise. Fertil Steril 2009.

to participate in the study. A physician reviewed their medical histories, ruling out possible reproductive alterations or childhood illnesses that could interfere with semen production (e.g., mumps, measles, varicocele, trauma to the genital area). The volunteers had no previous known infertility or hypothalamic-pituitary problems, although in most cases they had not fathered children. Exclusion criteria included, therefore, surgery or conditions that could impair reproduction, varicocele, and use of steroid hormones. Other factors that could interfere with the semen parameters were evaluated; such factors included diet, coffee, cigarette smoking, and alcohol consumption (evaluated through a 7-day qualitative and quantitative questionnaire), as well as possible occupational activities thought to exert a negative impact on semen quality, such as exposure to pesticides or paints or sitting for long hours in transportation means.

The inclusion criteria were related to exercise and to reproductive health, expressed as the following: not having any of the aforementioned exclusion criteria, practicing a minimum of $3 \mathrm{~h} / \mathrm{wk}$, and having a maximum oxygen uptake of at least $40 \mathrm{~mL} / \mathrm{min}$ per kilogram. A total of 45 subjects participated in the study. According to their own practice and training characteristics subjects were allocated to one of the following three groups: physically active subjects, water polo players, and triathletes (Fig. 1).

The first group was composed of physically active subjects $(\mathrm{n}=16)$ who did not practice any systematic resistance and power training but exercised three times a week, for 1 hour each session. The subjects in this group practiced several sports (basketball, soccer, tennis, paddle ball) and participated in local university competitions (nonprofessional). The second group was composed of water polo players $(\mathrm{n}=14)$. The subjects in this group were champions of the "provincial" league for the 2004 to 2005 season and had a more demanding training load, performing a total of five training sessions a week with 90 minutes duration each. The third group was composed of triathletes $(n=15)$. The subjects in this group were elite triathletes and participated in the "Ironman" competition. Their total weekly training volume was distributed as follows for each of the three disciplines (running [49.4 $\pm 7.4 \mathrm{~km}$ ], cycling [330.8 $\pm 56.0 \mathrm{~km}]$, and swimming $[11.3 \pm 3.0 \mathrm{~km}])$. The Ironman competition included $3.8 \mathrm{~km}$ of swimming, $180 \mathrm{~km}$ of biking, and 42.2 $\mathrm{km}$ of running. The characteristics of the subjects with regard to their backgrounds and morphofunctional and training status are given in Table 1.

\section{TABLE 1 \\ Subjects' demographics.}

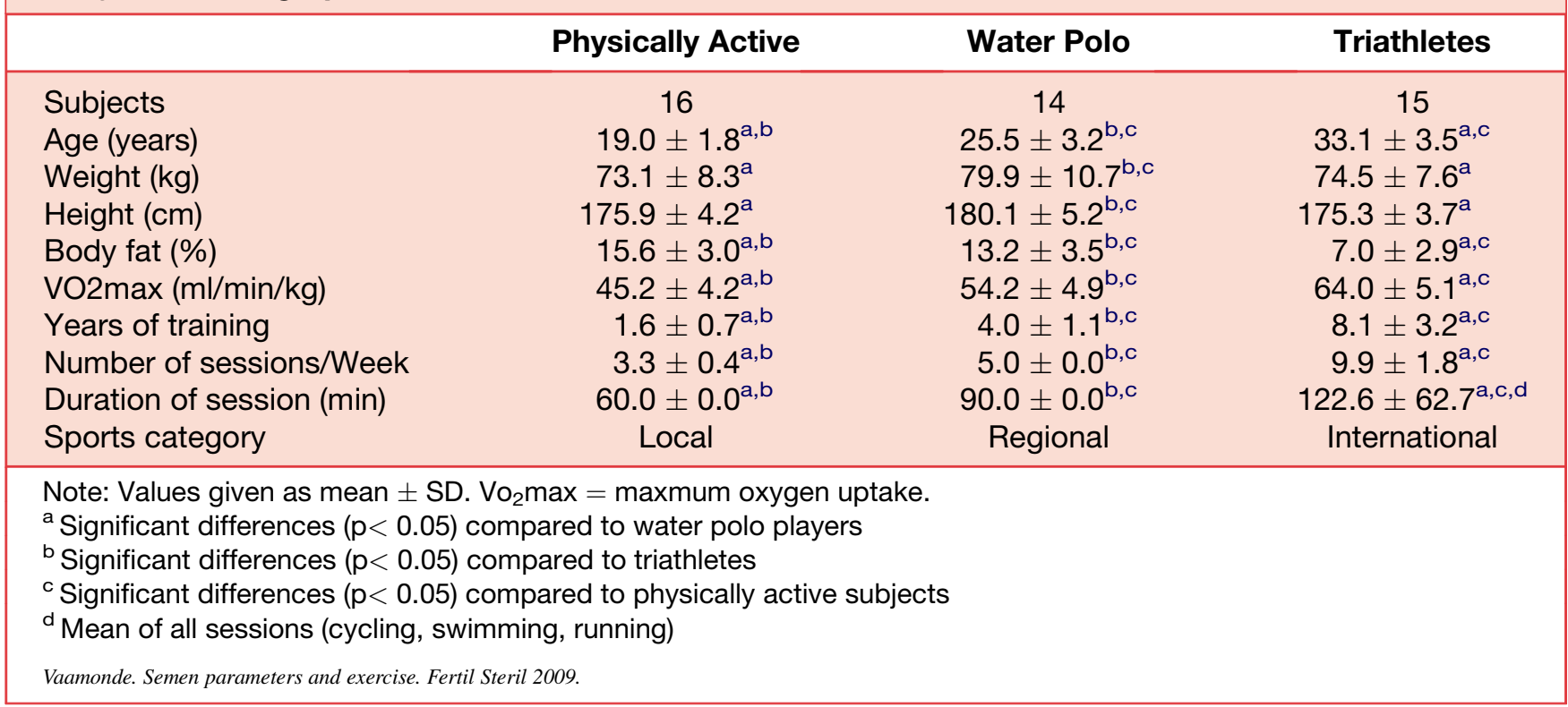




\section{TABLE 2}

Semen parameters from the subjects from the three different exercise groups.

\begin{tabular}{|c|c|c|c|c|}
\hline & \multicolumn{4}{|c|}{ Mean (SD) } \\
\hline & Physically Active & Water Polo & Triahtletes & $P$ value ${ }^{\mathrm{d}}$ \\
\hline Volume (ml) & $3.2 \pm 0.9$ & $3.4 \pm 1.3$ & $2.9 \pm 0.9$ & 0.48 \\
\hline Sperm concentration $\left(10^{6} / \mathrm{mL}\right)$ & $61.0 \pm 23.0^{\mathrm{b}}$ & $58.0 \pm 24.4^{b}$ & $48.2 \pm 14.7^{\mathrm{a}, \mathrm{c}}$ & 0.04 \\
\hline Total sperm number $\left(10^{6}\right)$ & $191.8 \pm 73.4^{b}$ & $196.6 \pm 85.4^{b}$ & $141.3 \pm 58.0^{\mathrm{a}, \mathrm{c}}$ & 0.03 \\
\hline \% Type "a" velocity & $31.1 \pm 9.7^{\mathrm{a}}$ & $23.6 \pm 8.8^{\mathrm{b}, \mathrm{c}}$ & $31.4 \pm 8.7^{\mathrm{a}}$ & 0.03 \\
\hline \% Type "b" velocity & $25.6 \pm 9.1^{\mathrm{b}}$ & $28.8 \pm 12.3^{b}$ & $18.9 \pm 7.6^{\mathrm{a}, \mathrm{c}}$ & 0.02 \\
\hline \% Type "a+b" velocity & $56.7 \pm 6.5$ & $52.5 \pm 11.1$ & $50.3 \pm 8.9$ & 0.34 \\
\hline \% Type "c" velocity & $10.4 \pm 5.0$ & $14.3 \pm 6.6$ & $11.9 \pm 6.3$ & 0.41 \\
\hline \% Type "d" velocity & $33.0 \pm 7.1^{b}$ & $33.3 \pm 11.3$ & $38.4 \pm 7.2^{\mathrm{c}}$ & 0.03 \\
\hline$\%$ Normal forms & $15.2 \pm 1.2^{\mathrm{a}, \mathrm{b}}$ & $9.7 \pm 3.0^{\mathrm{b}, \mathrm{c}}$ & $4.7 \pm 2.2^{\mathrm{a}, \mathrm{c}}$ & 0.01 \\
\hline \multicolumn{5}{|c|}{$\begin{array}{l}\text { a Significant differences }(p<0.05) \text { compared to water polo players } \\
\text { b Significant differences }(p<0.05) \text { compared to triathletes } \\
\text { c Significant differences }(p<0.05) \text { compared to physically active subjects } \\
\text { d One-way ANOVA and Sidak post hoc test for multiple comparisons }\end{array}$} \\
\hline \multicolumn{5}{|c|}{ Vaamonde. Semen parameters and exercise. Fertil Steril 2009.} \\
\hline
\end{tabular}

\section{Semen Analysis}

The participants had a 3- to 6-day sexual abstinence period preceding the semen sample collection and analysis. The triathlete and water polo subjects were assessed 2 weeks after the last competition and the last league match, respectively. For semen analysis the subjects ejaculated into sterile urine collection cups following the instructions given for the collection and handling of the sample. On arrival at the laboratory, they completed a brief questionnaire indicating days of abstinence and time of sample collection (arrival at the laboratory was within a half hour of collection time) and noting any sample collection problems. The macroscopic evaluation was performed 30 minutes after sample collection, when sample liquefaction was complete. In all cases complete liquefaction occurred within the normal established time range. The semen analysis included physical parameters (volume, $\mathrm{pH}$, liquefaction state, odor, color, absence or presence of agglutination and gelatinous bodies, and viscosity), as well as qualitative parameters of sperm (number, velocity, and morphology). We examined the ejaculate volume (expressed in milliliters), sperm concentration (expressed as million per milliliter), velocity (classified as "a," "b," "c," and "d" types), and morphology (expressed as percentage of normal forms) as the standards for sample normality as the World Health Organization recommends (19). Concentration and motility were assessed with use of the Makler chamber (Sefi Medical, Haifa, Israel). Sperm count was expressed as million per milliliter (concentration) or total number in millions. Regarding velocity, sperm were classified as having either type a, b, c, or d velocities. Type a were sperm that moved at $>20 \mu \mathrm{m} / \mathrm{s}$; type b moved at a speed between 5 and $20 \mu \mathrm{m} / \mathrm{s}$; type c moved at $<5 \mu \mathrm{m} / \mathrm{s}$, and type $\mathrm{d}$ were static. Two slides of sperm smears were made for morphology assessment in each case and stained with Diff-Quik stain (Dade Diagnos- tics, Miami, FL). Morphology slides were observed at $\times 1,000$ with immersion oil analyzing 200 sperm per slide, examining the head, midpiece, and tail with use of Kruger's strict criteria. In some cases, additional tests such as sperm vitality or sperm antibodies were needed. Vital Screen (Ferti Pro, Beernen, Belgium) was used for vitality testing, and Sperm Mar Test (Ferti Pro) was used for antibody testing; 200 sperm were analyzed for each test.

\section{Statistical Analysis}

On the basis of a pilot study (six subjects), as well as available literature, a power analysis was performed to determine the appropriate number of subjects. Fourteen subjects were required to detect a minimum difference of 25 million for total sperm number, $15 \%$ in type $\mathrm{a}+\mathrm{b}$ velocity, and $4 \%$ in morphology (Granmo 5.2 for Windows; IMIM, Barcelona, Spain); this would be required to achieve $80 \%$ statistical power.

Shapiro-Wilks tests were used to determine data normality for all dependent variables. Series of one-way analysis of variance (ANOVA) tests were used to compare groups for the descriptive variables. This analysis revealed an age difference between groups. Thus, analysis of covariance tests (ANCOVAs) were used with age as a covariance factor because of its effect on seminal parameters. A Sidak correction was used for multiple comparison purposes. Significance level was set at $P<.05$ (SPSS 10.0 for Windows; SPSS Inc., Chicago, IL).

\section{RESULTS}

All semen physical characteristics such as odor, color, and time to liquefaction were normal in all cases, and no differences were observed among groups. The values obtained 
for all the seminal parameters are shown in Table 2. It can be noted that the values for all parameters showed a trend toward higher values in the physically active group and lower for the water polo and triathlete groups, reaching statistical significance and, in some cases, even clinical significance as in the case of morphology. Thus, the sperm concentration was highest in the physically active group $\left(61.0 \times 10^{6} / \mathrm{mL}\right)$ followed by water polo $\left(58.0 \times 10^{6} / \mathrm{mL}\right)$ and then triathlete groups $\left(48.2 \times 10^{6} / \mathrm{mL}\right)$; ejaculate volume was similar for the water polo and physically active groups whereas it was lower for the triathletes. On the other hand, the total sperm number was highest in water polo players and physically active subjects and lowest in triathletes. With regard to sperm velocity, the physically active group showed higher values for type $a+b$ velocity and lower values for type $d$ velocity (Table 2). Sperm morphology results were the most noteworthy, with statistical and clinical relevant differences among the three groups ( $15.2 \%$ vs. $9.7 \%$ and $4.7 \%$ for physically active, water polo, and triathlete, respectively). The difference was statistically significant at $P<0.001$. It has to be noted that the percentage of normal forms for water polo and triathlete groups was below the limits of normality for Kruger's strict criteria.

\section{DISCUSSION}

The main finding of this study was that sperm morphology was significantly different among practitioners of the three analyzed groups. Other parameters such as sperm concentration, total sperm number, and sperm velocity showed a similar trend, albeit not as marked. Physical and macroscopic parameters were similar for the three groups and always in the range of normality. To the best of our knowledge this is the first study that analyzed differences in semen profiles of three groups of healthy individuals practicing different sport modalities.

Although sperm concentration was higher for the physically active group, total sperm number, a function of both concentration and ejaculate volume, was slightly higher in the water polo group. To the best of our knowledge, this is the first study to report data on water polo players. Previous studies have investigated mainly subjects who practice endurance sports. Ayers et al. (13) have observed that $10 \%$ of a sample of marathon runners exhibited severe oligospermia. We observed oligospermia in three of the triathlon subjects, although it was not severe (range of 1.3-1.8 mL).

The physically active group showed a trend for higher values of type $a+b$ velocity forms (not significant). Despite the fact that type a in water polo players and type $b$ in triathletes were below $25 \%$, all groups reached $50 \%$ in a + b, thereby suggesting no impairment of motility. Our findings seem to agree with those reported by other authors reflecting a higher value for seminal parameters in control subjects as compared with high-load exercise groups $(2,3,14,20)$; among those reports, only Arce et al. (14) found statistical differences. Statistically significant differences also were re- ported by our group when comparing physically active subjects who underwent high-intensity exercise with those who kept their regular routines (17).

The last seminal parameter to be analyzed was morphology. This structural test is gaining greater importance as a factor to be evaluated in human fertility analysis. Recent studies have correlated morphology with the outcome of assisted reproduction techniques (21-26), as well as with in vivo conception outcomes $(22,24)$. We have evaluated sperm according to Kruger's strict criteria $(27,28)$. Only the physically active group was above the $14 \%$ threshold value of Kruger's criteria (15.2\%, N-pattern) in contrast to the water polo group (9.7\%, G-pattern) and the triathlete group (4.7\%, P-pattern). These differences reached not only statistical significance but also clinical relevance in the case of triathletes, because individuals with $<5 \%$ normal forms are considered subfertile (29). One might speculate that differences in sperm morphology might be due to age differences observed between the groups; however, ANCOVA was used, and the test showed no effect of age on the analyzed parameter. Moreover, according to Chen et al. (30) the expected change in morphology would be a decrease of $1.06 \%$ per decade. Certainly, the differences observed for water polo players and triathletes are above that expected change.

Two factors that were not exercise related, water disinfection byproducts and water temperature, were excluded as possible causes of the observed alterations. The swimming pool where water polo players trained was treated via the method of saline chlorination, which greatly reduces a potential toxicity variable, because it provides more stable and reliable control of chlorine concentration. On the other hand, the pool temperature is normally kept at approximately $27^{\circ} \mathrm{C}$. Thus, it is likely that the differences observed in water polo players are due to inherent characteristics of their training.

We found significant differences in several parameters, with morphology being clearly the most altered; the triathletes showed a trend toward poorer seminal parameter values than the other two groups, and they are the only ones who perform very high training volume (running: $49.4 \mathrm{~km}$; swimming: $11.3 \mathrm{~km}$; cycling: $330.8 \mathrm{~km}$ ). Arce et al. (14) report that the athletes who exhibit differences in semen parameters are those with a minimum running volume of $100 \mathrm{~km} / \mathrm{wk}$. The triathletes analyzed in the present study did not have that running volume, but after adding the swimming and biking kilometers they surpassed it. It is difficult to find out which of the modalities they practice can affect sperm the most. Our study disagrees with the only other study that analyzed triathletes, because that study reported no significant differences in any of the seminal parameters (31); however, in measuring morphologic characteristics, those authors did not use strict criteria and analyzed the three sperm segments separately; perhaps differences could have been found if they had used more standardized morphologic analysis. There are studies analyzing biking $(5,31)$, running $(2,3$, $13,14)$, and swimming (32-34) that demonstrate differences 
in hormonal and semen parameters. Investigating cycling, Gebreegziabher et al. (5) reported only alterations in sperm morphology. Despite following World Health Organization regulations instead of Kruger's strict criteria, they found differences to be significant. Other authors reported diminished sperm velocity but only during the competition period (31). The subjects analyzed in the present study had been training for a long time and showed significant alterations for some parameters when compared with the physically active group. We must point out, however, that our subjects were in a training phase in which the load had been reduced considerably, because the evaluation was performed 2 weeks after they had participated in the Ironman competition; therefore, we may postulate that, as in the study by Lucia et al. (31), the values for the parameters could have been lower during competition or that because of the recent competition there still could be a residual effect on the parameters.

We have not assessed hormonal profiles in this study, which is a limitation; however, having analyzed the hormonal profile would have contributed only a limited insight because many times semen alterations occur without an associated hormonal abnormality. In fact, researchers still question whether hormone levels of FSH, LH, inhibin B, T, and thyroid hormones really have a predictive value on semen quality because the physiologic regulatory loops are rather complex and can be confounding (35). Moreover, sperm production is a rather long process requiring constant maintenance of testicular homeostasis; thus, although hormonal values can be altered and return to normal values, semen might not be able to revert to its normal physiologic state as readily.

Only five studies analyzed the effects of swimming on reproductive parameters; two exclusively assessed hormones in elite swimmers (observing contradictory results), and the other three analyzed reproductive capacity in rats. In rats submitted to heavy swimming, histologic sections through seminiferous tubules showed a decrease in spermatid number, which could be hazardous for reproductive health (34). Moreover, Manna et al. $(36,37)$ observed a decrease in several cell lineages, as well as enzymes related to sex hormones and antioxidant systems. Similar effects might be seen in humans if the stress due to exercise were high enough. In fact, it has been shown recently that the production of reactive oxygen species during moderate exercise provokes an increase in the expression of antioxidant enzymes, and, therefore, could be considered an antioxidant itself. On the contrary, all benefit is lost in exhaustive practice, possibly leading to oxidative damage and cell damage (38). In addition, it seems possible that the response might be dependant on the modality practiced (39-41). Moreover, Ironman triathletes have been shown to exhibit oxidative damage as a result of training and competition (39). We have mentioned the minimum running volume threshold $(3,15)$; however, as we have mentioned already, volume is not the only training parameter to consider relative to reproductive function. All influential parameters must be studied carefully in the training context, and an increase in scrotal temperature and reactive oxygen spe- cies production, which are well known to adversely influence seminal plasma and spermatozoa, should be avoided or minimized.

In conclusion, we observed that those practitioners systematically undergoing high training loads had altered values for semen parameters. Thus, we consider that although performance in these modalities needs such loads, palliative and compensatory aspects ought to be taken in consideration to dampen the effect of high-performance training. On the other hand, we observed that practicing a less demanding physical activity regularly does not seem to alter the values of normality of these parameters.

\section{REFERENCES}

1. Biolo G, Ciocchi B, Stulle M, Piccoli A, Lorenzon S, Dal Mas V, et al. Metabolic consequences of physical inactivity. J Ren Nutr 2005;15(1): 49-53.

2. Griffith RO, Dressendorfer RH, Fullbright CD, Wade CE. Testicular function during exhaustive endurance training. Phys Sportsmed 1990;18(5):54-64.

3. De Souza MJ, Arce JC, Pescatello LS, Scherzer HS, Luciano AA. Gonadal hormones and semen quality in male runners. A volume threshold effect of endurance training. Int J Sports Med 1994;15:383-91.

4. Di Luigi L, Gentile V, Pigozzi F, Parisi A, Giannetti D, Romanelli F. Physical activity as a possible aggravating factor for athletes with varicocele: impact on the semen profile. Hum Reprod 2001;16:1180-4.

5. Gebreegziabher Y, Marcos E, McKinon W, Rogers G. Sperm characteristics of endurance trained subjects. Int J Sports Med 2004;25:247-51.

6. De Souza MJ, Metzger DA. Reproductive dysfunction in amenorrheic athletes and anorexic patients: a review. Med Sci Sports Exerc 1991;23:995-1007.

7. Kopp-Woodroffe SA, Manore MM, Dueck CA, Skinner JS, Matt KS. Energy and nutrient status of amenorrheic athletes participating in a diet and exercise training intervention program. Int J Sport Nutr 1999;9:70-88.

8. De Souza MJ, Leidy HJ, O’Donnell E, Lasley B, Williams NI. Fasting ghrelin levels in physically active women: relationship with menstrual disturbances and metabolic hormones. J Clin Endocrinol Metab 2004;89:3536-42.

9. De Souza MJ, Luciano AA, Arce JC, Demers LM, Loucks AB. Clinical tests explain blunted cortisol responsiveness but not mild hypercortisolism in amenorrheic runners. J Appl Physiol 1994;76:1302-9.

10. Prather H, Hunt D. Issues unique to the female runner. Phys Med Rehabil Clin N Am 2005;16:691-709.

11. Klentrou P, Plyley M. Onset of puberty, menstrual frequency, and body fat in elite rhythmic gymnasts compared with normal controls. $\mathrm{Br} \mathrm{J}$ Sports Med 2003;37:490-4.

12. Valentino R, Savastano S, Tommaselli AP, D'Amore G, Dorato M, Lombardi G. The influence of intense ballet training on trabecular bone mass, hormone status, and gonadotropin structure in young women. Clin Endocrinol Metab 2001;86:4674-8.

13. Ayers JWT, Komesu V, Romani T, Ansbacher R. Anthropomorphic, hormone, and psychologic correlates of semen quality in endurance-trained male athletes. Fertil Steril 1985;43:917-21.

14. Arce JC, De Souza MJ, Pescatello LS, Luciano AA. Subclinical alterations in hormone and semen profile in athletes. Fertil Steril 1993;59:398-404.

15. De Souza MJ, Miller BE. The effect of endurance training on reproductive function in male runners. A "volume threshold" hypothesis. Sports Med 1997;23:357-73.

16. Jensen CE, Wiswedel K, McLoughlin J, van der Spuy Z. Prospective study of hormonal and semen profiles in marathon runners. Fertil Steril 1995;64:1189-96.

17. Vaamonde D, Da Silva ME, Poblador MS, Lancho JL. Reproductive profile of physically active men after exhaustive endurance exercise. Int J Sports Med 2006;27:680-9. 
18. Brock G. Erectile function of bike patrol officers. J Androl 2002;23: 758-9.

19. World Health Organization. Laboratory manual for examination of human semen and sperm-cervical mucus interaction. 4th ed. New York: Cambridge University Press, 1999.

20. Bagatell CJ, Bremner WJ. Sperm counts and reproductive hormones in male marathoners and lean controls. Fertil Steril 1990;53:688-92.

21. Kruger TF, Swanson RJ, Hamilton M, Simmons KF, Acosta AA, Matta JF, et al. Abnormal sperm morphology and other semen parameters related to the outcome of the hamster oocyte human sperm penetration assay. Int J Androl 1988;11:107-13.

22. Ombelet W, Menkveld R, Kruger TF, Steeno O. Sperm morphology assessment: historical review in relation to fertility. Hum Reprod Update 1995;1:543-57.

23. Burr RW, Siegberg R, Flaherty SP, Wang XJ, Matthews CD. The influence of sperm morphology and the number of motile sperm inseminated on the outcome of intrauterine insemination combined with mild ovarian stimulation. Fertil Steril 1996;65:127-32.

24. Ombelet W, Bosmans E, Janssen M, Cox A, Vlasselaer J, Gyselaers W, et al. Semen parameters in a fertile versus subfertile population: a need for change in the interpretation of semen testing. Hum Reprod 1997;12:987-93.

25. Kruger TF, Coetzee K. The role of sperm morphology in assisted reproduction. Hum Reprod Update 1999;5:172-8.

26. Van Waart J, Kruger TF, Lombard CJ, Ombelet W. Predictive value of normal sperm morphology in intrauterine insemination (IUI): a structured literature review. Hum Reprod Update 2001;7:495-500.

27. Menkveld R, Kruger TF. Advantages of strict (Tygerberg) criteria for evaluation of sperm morphology. Int J Androl 1995;18(Suppl 2):36-42.

28. Franken DR, Smith M, Menkveld R, Kruger TF, Sekadde-Kigondu C, Mbizvo M, et al. The development of a continuous quality control programme for strict sperm morphology among sub-Saharan African laboratories. Hum Reprod 2000;15:667-71.

29. Siebert T, van der Merwe H, Kruger T, Ombelet W. How do we define male subfertility and what is the prevalence in the general population? In: Oehninger S, Kruger T, eds. Male infertility: diagnosis and treatment. London: Informa Healthcare, 2007:269-76.
30. Chen Z, Toth T, Godfrey-Bailey L, Mercedat N, Schiff I, Hauser R. Seasonal variation and age-related changes in human semen parameters. J Androl 2003;24:226-31.

31. Lucia A, Chicharro JL, Perez M, Serratosa L, Bandres F, Legido JC. Reproductive function in male endurance athletes: sperm analysis and hormonal profile. J Appl Physiol 1996;81:2627-36.

32. Bonifazi M, Bela E, Carli G, Lodi L, Martelli G, Zhu B, et al. Influence of training on the response of androgen plasma concentrations to exercise in swimmers. Eur J Appl Physiol Occup Physiol 1995;70:109-14.

33. Mackinnon LT, Hooper SL, Jones S, Gordon RD, Bachmann AW. Hormonal, immunological, and hematological responses to intensified training in elite swimmers. Med Sci Sports Exerc 1997;29:1637-45.

34. Mingoti GZ, Pereira RN, Monteiro CM. Fertility of male adult rats submitted to forced swimming stress. Braz J Med Biol Res 2003;36:677-81.

35. Meeker JD, Godfrey-Bailey L, Hauser R. Relationships between serum hormone levels and semen quality among men from an infertility clinic. J Androl 2007;28:397-406.

36. Manna I, Jana K, Samanta PK. Intensive swimming exercise-induced oxidative stress and reproductive dysfunction in male wistar rats: protective role of alpha-tocopherol succinate. Can J Appl Physiol 2004;29: $172-85$.

37. Manna I, Jana K, Samanta PK. Effect of different intensities of swimming exercise on testicular oxidative stress and reproductive dysfunction in mature male albino Wistar rats. Indian J Exp Biol 2004;42:816-22.

38. Gomez-Cabrera MC, Domenech E, Viña J. Moderate exercise is an antioxidant: upregulation of antioxidant genes by training. Free Radic Biol Med 2008;44:126-31.

39. Knez WL, Jenkins DG, Coombes JS. Oxidative stress in half and full Ironman triathletes. Med Sci Sports Exerc 2007;39:283-8.

40. Dékány M, Nemeskéri V, Györe I, Harbula I, Malomsoki J, Pucsok J. Antioxidant status of interval-trained athletes in various sports. Int J Sports Med 2006;27:112-6.

41. Kostaropoulos IA, Nikolaidis MG, Jamurtas AZ, Ikonomou GV, Makrygiannis V, Papadopoulos G, et al. Comparison of the blood redox status between long-distance and short-distance runners. Physiol Res 2006;55:611-41. 